\title{
Using genomics to enhance selection of novel traits in North American dairy cattle ${ }^{1,2}$
}

\author{
J. P. Chesnais, ${ }^{* 3}$ T. A. Cooper,† G. R. Wiggans, † M. Sargolzaei, ${ }^{*} \ddagger$ J. E. Pryce, $§$ and F. Miglior \#\# \\ *The Semex Alliance, Guelph, ON N1G 3Z2, Canada \\ †Animal Genomics and Improvement Laboratory, Agricultural Research Service, USDA, Beltsville, MD 20705-2350 \\ $\ddagger$ Centre for Genetic Improvement of Livestock, Department of Animal Biosciences, University of Guelph, Guelph, ON N1G 2W1, Canada \\ §Department of Economic Development, Jobs, Transport and Resources, Bundoora, Victoria 3083, Australia \\ \#Canadian Dairy Network, Guelph, ON N1K 1E5, Canada
}

\section{ABSTRACT}

The objectives of this paper were to briefly review progress in the genetic evaluation of novel traits in Canada and the United States, assess methods to predict selection accuracy based on cow reference populations, and illustrate how the use of indicator traits could increase genomic selection accuracy. Traits reviewed are grouped into the following categories: udder health, hoof health, other health traits, feed efficiency and methane emissions, and other novel traits. The status of activities expected to lead to national genetic evaluations is indicated for each group of traits. For traits that are more difficult to measure or expensive to collect, such as individual feed intake or immune response, the development of a cow reference population is the most effective approach. Several deterministic methods can be used to predict the reliability of genomic evaluations based on cow reference population size, trait heritability, and other population parameters. To provide an empirical validation of those methods, predicted accuracies were compared with observed accuracies for several cow reference populations and traits. Reference populations of 2,000 to 20,000 cows were created through random sampling of genotyped Holstein cows in Canada and the United States. The effects of single nucleotide polymorphisms (SNP) were estimated from those cow records, after excluding the dams of validation bulls. Bulls that were first prog-

Received June 15, 2015.

Accepted November 20, 2015.

${ }^{1}$ The use of trade, firm, or corporation names in this publication is for the information and convenience of the reader. Such use does not constitute an official endorsement or approval by USDA or the Agricultural Research Service of any product or service to the exclusion of others that may be suitable.

${ }^{2}$ Presented as part of the Joint Interbull/JAM Symposium: Use of Genomics to Improve Limited and Novel Phenotypes in Animal Breeding at the ADSA-ASAS Joint Annual Meeting, Orlando, Florida, July 2015.

${ }^{3}$ Corresponding author: jpchesnais@rogers.com eny tested in 2013 and 2014 were then used to carry out a validation and estimate the observed accuracy of genomic selection based on those SNP effects. Over the various cow population sizes and traits considered in the study, even the best prediction methods were found, on average, to either under-evaluate observed accuracy by 0.20 or over-evaluate it by 0.22 , depending on the approach used to estimate the number of independently segregating chromosome segments. In some instances, differences between observed and predicted accuracies were as large as 0.47 . Indicator traits can be very useful for the selection of novel traits. To illustrate this, protein yield, body weight, and mid-infrared data were used as indicator traits for feed efficiency. Using those traits in conjunction with 5,000 cow records for dry matter intake increased the reliability of genomic predictions for young animals from 0.20 to 0.50 .

Key words: genetic evaluation, novel trait, prediction accuracy, genomics, selection

\section{INTRODUCTION}

For many years, dairy cattle selection has focused primarily on milk production and cow conformation; however, many functional traits have negative correlations with production, which has led to reductions in health and fitness. Several traits were introduced in North American selection objectives over the last 10 to $20 \mathrm{yr}$ to address this issue, notably SCS, herd life or productive life (longevity), and daughter fertility traits. In addition, several traits affect product quality, cost efficiency, and the environmental impact of dairying. These traits are gaining in importance in the industry, and genomics provides new opportunities for their selection. The objectives of this paper were to carry out a brief review of the status of research and genetic evaluation for those novel traits, to assess their expected selection accuracy in industry selection schemes, and to illustrate how the use of indicator traits could increase that accuracy. 


\section{BRIEF REVIEW OF NOVEL TRAITS IN NORTH AMERICA}

A comprehensive review of novel traits in dairy cattle can be found in Egger-Danner et al. (2015a). That review provides useful information on worldwide research for those traits and on phenotyping strategies that can be used for their selection. An existing trait in one country may be a novel trait in another. Scandinavian countries, in particular, have accumulated data and produced genetic evaluations for many health traits that are novel in other countries. In the current study, the purpose was to provide a brief description of the status of selection for novel traits in North America, including activities expected to lead to national genetic evaluations for those traits within the next 5 yr. Table 1 summarizes current status separately for Canada and the United States, including for each trait of (a) no or very little research, (b) actively researched, (c) preliminary evaluations produced, or (d) national evaluations officially implemented. Traits were categorized as udder health, hoof health, other health traits, feed efficiency and methane emissions, or other novel traits. For actively researched traits, only research projects undertaken with the goal of providing national evaluations over the next 5 yr were described.

\section{Udder Health}

Several studies have shown that incorporating mastitis incidence data into breeding value estimation can improve genetic progress for mastitis resistance compared with the use of SCS alone (Heringstad et al., 2007). In Canada, the development of a national health-recording program began in 2007 as collaboration between the Canadian Dairy Network (CDN; Guelph, ON, Canada) and Canadian DHI organizations and has led to the collection of large amounts of data on mastitis incidence. Those incidence data, which are recorded by producers or veterinarians, are analyzed in a multitrait model with data on SCS and other indicator traits (namely, mean SCS in early lactation, standard deviation of SCS, excessive test-day SCC, fore udder attachment, udder depth, and BCS) to produce traditional as well as genomic evaluations for mastitis resistance (Koeck et al., 2012a,c; Jamrozik et al., 2013; Miglior et al., 2014). Genomic breeding values for mastitis resistance have been published officially in Canada since August 2014 and have become part of national selection indices (Pro $\$$, a new profit-based index expressed in dollar terms, and LPI, the current lifetime performance index; Beavers and Van Doormaal, 2015) since August 2015.

Table 1. Novel traits with ongoing research or official evaluations in the United States and Canada $(\mathrm{AR}=$ actively researched; $\mathrm{PE}=$ preliminary evaluations produced; $\mathrm{OE}=$ official evaluations nationally implemented)

\begin{tabular}{|c|c|c|}
\hline Trait & $\begin{array}{l}\text { United } \\
\text { States }\end{array}$ & Canada \\
\hline \multicolumn{3}{|l|}{ Udder health } \\
\hline Alternative definitions of SCS & - & $\mathrm{OE}$ \\
\hline New predictors of mastitis incidence [conductivity, mid-infrared (MIR)] & - & AR \\
\hline Hoof health (hoof trimming, locomotion, lameness) & AR & $\mathrm{PE}$ \\
\hline \multicolumn{3}{|l|}{ Other health traits } \\
\hline Metabolic diseases [incidence of ketosis, displaced abomasum, predictors (e.g., BHB, fat:protein ratio)] & AR & $\mathrm{PE}$ \\
\hline Resistance to Johne's disease (Mycobacterium avium ssp. paratuberculosis) & AR & $\mathrm{AR}$ \\
\hline Immune response (antibody, cell-mediated) & - & $E^{1}$ \\
\hline \multicolumn{3}{|l|}{ Feed efficiency and methane emissions } \\
\hline $\begin{array}{l}\text { Individual feed intake [e.g., DMI, residual feed intake, energy balance, predictors (production, direct or indirect } \\
\text { cow weight, MIR)] }\end{array}$ & AR & $\mathrm{AR}$ \\
\hline Emission of methane (calorimeter, other methods) and predictors (e.g., MIR) & AR & AR \\
\hline \multicolumn{3}{|l|}{ Workability } \\
\hline Number of embryos produced (for embryo transfer) & - & $\mathrm{AR}$ \\
\hline Profit per cow to 6 yr of age & - & $\mathrm{OE}^{2}$ \\
\hline Milk composition (fatty acids, lactoferrin) and predictors (e.g., MIR) & - & AR \\
\hline
\end{tabular}

${ }^{1}$ Evaluations within one AI organization.

${ }^{2}$ Used for derivation of a national selection index. 
In the United States, research results on the genetics of health traits were reported as early as 2004 (Zwald et al., 2004a,b). In a recent study (Parker Gaddis et al., 2014), genetic analyses were performed using approximately 300,000 records of health events contributed by producers to a US dairy record processing center from 1996 through 2012. Those records were categorized into broad areas, including reproductive problems, metabolic diseases, and lameness, as well as mastitis. The authors concluded that genetic selection for health traits using producer-recorded data is feasible in the United States and that the inclusion of genomic data would substantially improve selection accuracy. Other indicator traits (such as the electrical conductivity of milk) have been proposed to help predict mastitis incidence (Fernando et al., 1985; Goodling et al., 2000). The addition of this information may increase the accuracy of breeding values, but research is still required to confirm this. National genetic and genomic evaluations for udder and other health traits are not being planned currently in the United States, but discussions are ongoing regarding the development of a national health-recording program that could facilitate this goal in the future (J. M. Mattison, National Dairy Herd Information Association, Verona, WI; personal communication).

\section{Hoof Health}

Improving hoof health (or claw health, as it is usually called in the United States) is a major goal for the dairy cattle industry in North America (as in many other countries), given the prevalence of lameness and hoof health problems in dairy herds (Cramer et al., 2008). In the United States and Canada, genetic evaluations for conformation traits of feet and legs have been available for several decades. However, indirect genetic selection for hoof health through conformation traits has not been very effective. In particular, correlations between infectious claw lesions and feet and leg traits (e.g., foot angle, heel depth, bone quality, rear leg view, and locomotion) are low (van der Waaij et al., 2005; Chapinal et al., 2013). To select effectively for hoof health, single claw lesions reported by hoof trimmers must be considered. Consistency of diagnosis and data recording is important, which was the motivation behind the development of a claw health atlas by the International Committee for Animal Recording (http:// www.icar.org/Documents/ICAR_Claw_Health_Atlas. pdf; Egger-Danner et al., 2015b). Electronic data capture using handheld devices has made recording information on hoof disorders easier. For example, Hoof Supervisor (Dresser, WI) helps in standardizing the definition of symptoms, allows electronic data capture, and produces on-farm reports.

In Canada, several regional projects have been carried out between 2010 and 2013. The accumulated hoof health data have been used to calculate heritabilities and genetic correlations for various hoof health traits (Chapinal et al., 2013; Malchiodi et al., 2015). A national project is now underway to develop an interface for data exchange between hoof trimmers and Canadian DHI and between Canadian DHI and CDN and to produce genetic and genomic evaluations for key hoof health traits within the next $3 \mathrm{yr}$. At this point, traits such as the incidence of digital dermatitis and of sole ulcers appear to be the most promising. Trait definitions for hoof infections and horn lesions in Canada are now fully aligned with the standards recently published by the International Committee for Animal Recording (Egger-Danner et al., 2015b). In the United States, several promising studies have been completed using hoof-trimmer data (Oberbauer et al., 2013; Dhakal et al., 2015b), but currently no plans have been made to proceed with national evaluations for hoof health traits.

Two other related traits that have been recorded in Canada for several years are lameness and locomotion. Lameness is recorded as part of the national healthrecording program, and locomotion is recorded as a research trait by Holstein Canada (Brantford, ON, Canada). Because a database now exists for those traits, they may become part of the national genetic evaluation for hoof health, where they would be used in association with hoof-trimmer data.

\section{Other Health Traits}

Reproductive Disorders. Reproductive disorders such as retained placenta, metritis, and cystic ovaries are affected mostly by herd management and environmental factors and have low heritabilities (Koeck et al., 2012b, 2015a; Cole et al., 2013; Berry et al., 2014b; Parker Gaddis et al., 2014; Dhakal et al., 2015a). However, significant differences in daughter incidence do exist among sires. In Canada, these traits are recorded as part of the national health-recording program. They are also recorded by some dairy record processing centers in the United States. Given their low heritability and the lack of suitable indicator traits, the development of genetic or genomic evaluations for these traits has not been given a high priority, although it remains a long-term possibility.

Superovulation. Superovulation and embryo transfer have been used in North America for at least $20 \mathrm{yr}$ to increase the reproduction rate of females with high genetic potential. They have become even more instru- 
mental in the selection process over the last few years in combination with in vitro fertilization by permitting the production of relatively large numbers of progeny from top young females, which can then be screened based on their genomic evaluations. In Canada, research has begun on the analysis of the number of total and viable embryos produced per flush for $>135,000$ flushes from 54,000 cows. Preliminary research indicates heritabilities of 0.14 to 0.17 for these traits as well as significant genetic differences among sires (Jaton et al., 2015). Genomic analysis shows that a few QTL may have a large influence (Jaton et al., 2015). Research is continuing, but no plan has been formulated yet for its application. In the United States, a SNP associated with superovulation response was found to be associated with heifer conception rate and productive life (Cochran et al., 2013).

Metabolic Diseases. Metabolic diseases include ketosis, milk fever, and displaced abomasums, which are of significant economic concern to the dairy cattle industry. Ketosis, in particular, has a relatively high frequency, with a mean of $5.1 \%$ for first parities and $11.6 \%$ for later parities in Canada (Koeck et al., 2015b) and $10 \%$ in the United States (Zwald et al., 2004a). For some years now, testing of milk BHB has made it possible to detect subclinical levels of ketosis before the disease occurs clinically (Geishauser et al., 2000). At the same time, BHB tests provide a new way of selecting against both ketosis and milk fever. In Canada, BHB tests are carried out primarily by milk-recording organizations (CanWestDHI, Guelph, ON, Canada; Valacta, Sainte-Anne-de-Bellevue, QC, Canada). Therefore, records can be centralized and associated with ketosis incidence data from the national health-recording program. Recent studies (Koeck et al., 2015b; Jamrozik et al., 2016) showed that genetic and genomic selection for resistance to ketosis is quite possible because of the strong genetic correlation between ketosis incidence and BHB (0.75) and the heritability of 0.10 to 0.13 for $\mathrm{BHB}$, which is relatively high for health traits. A study of SNP associated with subclinical ketosis in US Jerseys (Fugate et al., 2014) reported that genotypes could be useful for predicting predisposition for ketosis. Another promising avenue is the use of mid-infrared (MIR) data to predict ketosis because of its association with energy balance (Gengler et al., 2015). In the United States, data from on-farm herd management systems may be sufficient for routine calculation of genetic and genomic evaluations for most common health disorders of US Holsteins (Clay et al., 2013; Cole et al., 2013). Canadian genetic and genomic evaluations for resistance to metabolic disease traits are being planned for 2016 .

Johne's Disease. Using genomics to select for resistance to Mycobacterium avium ssp. paratuberculosis
(MAP), the bacterium known to cause Johne's disease, has been the subject of several research projects in North America (Zare et al., 2014a,b). In Canada, these projects have focused primarily on attempting to understand mechanisms underlying the disease. Preliminary research has also begun on the analysis of milk test records for MAP collected by CanWest DHI. However, the relatively low frequency of MAP recorded in the Canadian DHI database has been a challenge, and implementation of any genetic-based program to increase resistance to MAP may take several years. Although some research has taken place in the United States based on MAP data collected through various programs (Byrem et al., 2009; Attalla et al., 2010), US national evaluations for resistance to MAP are not planned at this time (J. B. Cole, Animal Genomics and Improvement Laboratory, Agricultural Research Service, USDA, Beltsville, MD; personal communication).

Immune Response. Selection for general resistance to disease represents an interesting and promising avenue to reduce disease levels in dairy herds. Sonstegard and Gasbarre (2001) discussed the possibility of using genomic tools to improve parasite resistance. Research carried out over the last $10 \mathrm{yr}$ in both Canadian and US herds indicates that animals with higher immune response have lower levels of disease (e.g., mastitis and metritis), produce higher quality colostrum, and respond better to vaccines (Thompson-Crispi et al., 2012, 2014a,b). In Canada, proprietary technology developed by the University of Guelph (Guelph, ON, Canada) for the selection of high immune response is now used on a routine basis by one AI organization (Mallard et al., 2014). A reference population of 2,000 bulls and 5,000 cows is being developed with the objective of introducing genomic selection for 2 key traits: antibody-mediated immune response and cell-mediated immune response.

\section{Feed Efficiency and Methane Emissions}

Feed Efficiency. Feed accounts for as much as 50\% of costs on dairy farms in North America, and feed costs have been increasing over the last few years. As a result, there is considerable interest in developing ways to select for cow feed efficiency, which can generally be defined as units of output per unit of input at the farm level or for an individual animal. The lack of availability of individual feed intake data has been the greatest obstacle to selection for feed efficiency (Berry and Crowley, 2013). The 2 options that are likely to provide sufficient selection accuracy despite the limited amount of phenotypes are the use of indicator traits (Fogh et al., 2013) and genomic prediction (Pryce and Berry, 2014). Several research centers in North America [CDN, 
the University of Alberta (Edmonton, AB, Canada), Iowa State University (Ames, IA), and the University of Wisconsin (Madison, WI)] have participated in the global Dry Matter Initiative, which includes 10 research herds from 9 countries (Australia, Canada, Denmark, Germany, Ireland, the Netherlands, New Zealand, United Kingdom, and United States). The Initiative's goal is to combine feed intake records from different sources to create a large cow reference population for genomic selection of DMI (de Haas et al., 2015).

In Canada, individual feed intake data have been collected for many years at the University of Alberta on a limited scale, but a new research facility has just opened at the University of Guelph. A project to increase feed efficiency and reduce methane emissions has been funded through Genome Canada (Ottawa, ON, Canada) with several Canadian participants and partners in the United States, United Kingdom, Australia, and Switzerland; the 4-yr project began in late 2015 (Genome Alberta, 2015). A new feature of this project is the collection of individual feed intake data using specialized equipment in a few sponsored commercial farms so that data collection costs can be reduced compared with those incurred in a typical research herd. Phenotypes such as residual feed intake will be examined using genotyped populations so that development of genomic predictions can be investigated for this trait.

In the United States, several initiatives on feed efficiency have already taken place. A large cooperative project involving Iowa State University, Michigan State University (East Lansing, MI), North Carolina Agricultural and Technical State University (Greensboro, NC), Virginia Polytechnic Institute and State University (Blacksburg, VA), the University of Florida (Gainesville, FL), and Wageningen University (Wageningen, the Netherlands) began in 2011. The project will result in the collection and analysis of feed intake records on up to 8,000 cows by the time it is completed in 2016 . The research to date has focused on the methodology and statistical issues arising from combining data from multiple sources (Spurlock et al., 2014; Tempelman et al., 2015). Genomic evaluations for feed efficiency based on data collected through these projects (and possibly data from international cooperators) are, therefore, likely to become a reality over the next few years. In the meantime, Holstein Association USA (Brattleboro, VT) has introduced a feed efficiency component in its selection index, which is a function of production and predicted cow weight designed to approximate maintenance requirements. Currently, this measure does not account for variation between individuals in their efficiency of converting an equivalent amount of feed into product.
Methane Emissions. Part of the environmental impact of dairying is the emission of methane gas by cows, which contributes to climate change. Increased production per cow has allowed the industry to substantially reduce methane emissions per kilogram of milk produced. The North American dairy cattle industry, however, has been looking for additional ways to reduce methane emissions. Various methods are available for measuring methane emissions, from calorimetry chamber (the gold standard) to devices that can be secured to the animal (METHAGENE, 2015). All these methods are expensive and do not allow for data collection of methane emissions on a very large scale. A more promising avenue for selection for reduced methane emission is through indirect selection. Recent research (Dehareng et al., 2012; McParland et al., 2014) has shown that MIR spectral data could serve as a useful predictor of feed efficiency. Furthermore, the same research indicates that a genetic increase in feed efficiency is associated with a decrease in methane emission. Several research projects are underway in North America, including the feed efficiency projects cited earlier, to investigate this issue further.

\section{Other Novel Traits}

MIR Spectral Data. Most livestock industries have been selecting for product composition to enhance the value of their product to the consumer. In dairy cattle breeding, the main criteria for selection have been protein and fat composition of milk. New technology is now available, however, to probe milk composition further. In particular, some of the laboratory equipment used by DHI organizations for the analysis of milk, which is based on the MIR spectrum, offers new opportunities for predicting milk content of various fatty acids and of other components such as lactoferrin (Soyeurt et al., 2010, 2011; De Marchi et al., 2014). In Canada, about 2.4 million MIR records from 600,000 cows have been collected by Canadian DHI organizations since 2013, and a project is now underway to develop a centralized database for these records; develop predictions for milk composition, feed efficiency and methane emissions; and produce genetic and genomic evaluations for some of these MIR predictions. The MIR project began in 2014 and will be completed in 2018. In the United States, discussions are underway among DHI organizations to determine how much MIR data are available and whether they could be used for the same purposes (J. M. Mattison, National Dairy Herd Information Association, Verona, WI; personal communication).

Workability. Other novel traits could be related to cow workability; that is, traits that facilitate working 
with cows on the farm. In Canada, official genetic evaluations for milking speed and milking temperament have been available for more than $20 \mathrm{yr}$ and are no longer considered to be novel there. The main purpose of such evaluations is to identify sires that produce daughters with undesirable milking speed or temperament. Attention to these traits has increased recently because of their effect on robotic milking, which is becoming more common in the industry. The data consist of subjective ratings provided by dairy producers. Before official evaluations began for milking speed, subjective rankings were compared with milk flow measurements and found to be in good agreement. Genomic evaluations for both traits have been published in Canada since 2009. There is no immediate plan to introduce evaluations for these traits in the United States.

Profitability. Traditionally, total indices of genetic merit are designed to predict total profit and combine breeding values weighted by their respective economic values. However, a novel approach is to calculate the profitability of the cow itself and use this as a phenotype. In Canada, an evaluation of profit per cow to 6 yr of age became available in August 2015. Canadian DHI organizations calculate and report to their members the accumulated profit per cow until the cow is culled; variables such as milk and component prices, maintenance and marginal feed costs, and heifer rearing costs are taken into account. Those data were used to derive the new selection index Pro\$, which weights all traits evaluated to date in a way that maximizes for the function of profit per cow to $6 \mathrm{yr}$ of age (Beavers and Van Doormaal, 2015). This approach has 2 advantages. First, the new trait relates directly to the economic data that producers receive from DHI, which is expected to facilitate acceptance by producers. Second, the new index inherently accounts for correlations between all component traits, something that many selection indices used today are not doing and which can result in less than an economic optimum.

\section{SELECTION OF NOVEL TRAITS}

Most selection today in North America is carried out on young animals (young bulls or heifers) using genomic evaluations. In Canada, only bulls are used in the reference population, whereas both bulls and cows are used in the United States. Novel traits tend to come in 2 categories, leading to 2 different selection approaches. The first category includes traits that are relatively inexpensive to collect through DHI or other recording programs and for which a large database is already available in some cases. Examples include milking speed and temperament in Canada, disease incidence or claw health (hoof trimmer data), milk MIR data, and milk tests associated with MAP. For such traits, the main challenges are ensuring national standardization of data collection and the development or expansion of a national database. Once standardized records are available, genetic parameters can be estimated and traditional evaluations carried out using either a sire or an animal model. Because data collection usually occurs on a large scale, sires tend to have large numbers of daughters with records. In addition, these sires have already been genotyped by the industry as a prerequisite for genomic selection of current traits. Therefore, the easiest and cheapest route for genetic improvement is to develop genomic evaluations based on deregressed traditional sire evaluations or to use a one-step genetic evaluation model that uses phenotypes and genotypes directly for the same purpose. For such traits, the same genomic evaluation pipeline that already exists for current traits can be used. The difficult part is organizing the standardization and centralized storage of the data.

The second category of traits includes those that are expensive or difficult to record. Examples are feed efficiency, methane emission, and immune response. For such traits, a new database usually needs to be constructed, often at considerable expense; for example, an individual feed efficiency record may cost from $\$ 250$ to $\$ 1,000$ to collect. Given this expense, genotyping all animals with phenotypes is more efficient than using, for example, the genotypes of their sires, even if those are already available. The use of a cow reference population is, therefore, the most cost-effective way to generate genomic evaluations for such traits (Van Grevenhof et al., 2012; Calus et al., 2013).

The formula derived by Daetwyler et al. (2008) provides a simple and convenient means to compare the prediction accuracy of different scenarios based on either a sire or cow reference population. With this formula, the reliability (REL) of genomic predictions is calculated as

$$
\mathrm{REL}=\mathrm{Nh}^{2} /\left(\mathrm{Nh}^{2}+\mathrm{M}_{\mathrm{e}}\right),
$$

where $\mathrm{N}$ is the number of individuals in the reference population that have both a genotype and a breeding value, $h^{2}$ is the REL of each breeding value (equal to the heritability of the trait if an animal is evaluated based only on its own phenotype), and $\mathrm{M}_{\mathrm{e}}$ is the number of independently segregating chromosome segments. The value $\mathrm{M}_{\mathrm{e}}$ can be calculated as $\mathrm{M}_{\mathrm{e}}=2 \mathrm{~N}_{\mathrm{e}} \mathrm{L}$, where $\mathrm{N}_{\mathrm{e}}$ is the effective population size and $\mathrm{L}$ is the length of the genome in Morgans (assumed to be 30 for cattle; Hayes et al., 2009b). Daetwyler et al. (2008) 
also introduced a correction to this formula, which is to add $\mathrm{REL}^{4} \mathrm{M}_{\mathrm{e}} / 2 \mathrm{~N}$ to the value of REL above. All formula values presented in this paper include this correction. In Stachowicz et al. (2011), the effective size of the Canadian Holstein population was estimated to be 115. More recent work by Larmer (2012) estimated the effective size of the Holstein population to be 153 at 20 generations ago, 109 at 9 generations ago, and 99 at 6 generations ago. Extrapolation of this trend leads to a mean effective population size of 85 on average over the last 2 to 3 generations. An $\mathrm{N}_{\mathrm{e}}$ of 100 was assumed, which is intermediate to the estimates of Stachowicz et al. (2011) and Larmer (2012).

Based on the above formulas, the reliabilities of genomic predictions were calculated for various heritabilities and numbers of sires (and daughters per sire) or cows in the reference population (Table 2). In addition, the total cost of each scheme is shown for 2 phenotyping costs: $\$ 1$ or $\$ 100$ per cow phenotype. This cost corresponds to the accumulation of phenotypes and genotypes (potentially over several years) needed to achieve the stated level of accuracy. Sires are assumed to be already genotyped (i.e., no additional cost is associated with their genotyping), and the cost of genotyping cows is assumed to be $\$ 80$ per cow. When the cost of phenotyping was $\leq \$ 1$, using a sire reference population (or potentially both sires and cows) was advantageous. This is especially true for low-heritability traits, for which the use of progeny-based evaluations leads to moderately accurate genomic predictions at a reasonable cost $(<\$ 1$ million). However, as soon as the cost of phenotyping increases, the cost of a sire scheme becomes too high, and using a cow reference population is necessary. The worst situation occurs for any trait for which the cost of phenotyping is high and the heritability is low. In such a case, the cow reference scheme requires a considerable number of animals for adequate prediction accuracy, and the sire reference scheme becomes prohibitively expensive.
The Daetwyler formula relies on relatively simple theoretical assumptions such as the number of independently segregating chromosome segments. Some comparisons between formula predictions and observed estimates of accuracy from genomic validation studies have been made in the past (Hayes et al., 2009a; Wientjes et al., 2013; Brard and Ricard, 2015) but mostly for sire reference populations. Very few comparisons have been made for cow reference populations. The study of Brard and Ricard (2015) used data from 13 articles, but 7 were based on simulated data and all others were based on sire reference populations. In Wientjes et al. (2013), comparisons between methods were based on simulated genotypes, with the exception of one empirical comparison based on a reference population of only 529 cows for only one trait.

Several countries in North America and elsewhere have been developing or considering the development of cow reference populations for various traits, with their high inherent cost. The empirical validation of prediction formulas would therefore be useful for assessing what population size is required to achieve a minimum accuracy level. In the next section, we used the Canadian and US genotyped Holstein cow populations to carry out such a validation. This objective does not require the use of novel traits because the Daetwyler formula applies to any trait, not just novel traits. In fact, validation of the formula is more effective using existing traits for which sufficient genotypes and phenotypes have already been accumulated. Then, heritability estimates are more reliable and observed reliabilities of direct genomic values can be readily computed. Traits used in the validation were chosen to represent a wide range of heritabilities to test the effect of heritability on accuracy of prediction.

The amount by which indicator traits can increase prediction accuracy is another question associated with the development of cow reference populations. To shed some light on this question, an example based on DMI

Table 2. Reliability and comparative costs of various reference populations ${ }^{1}$

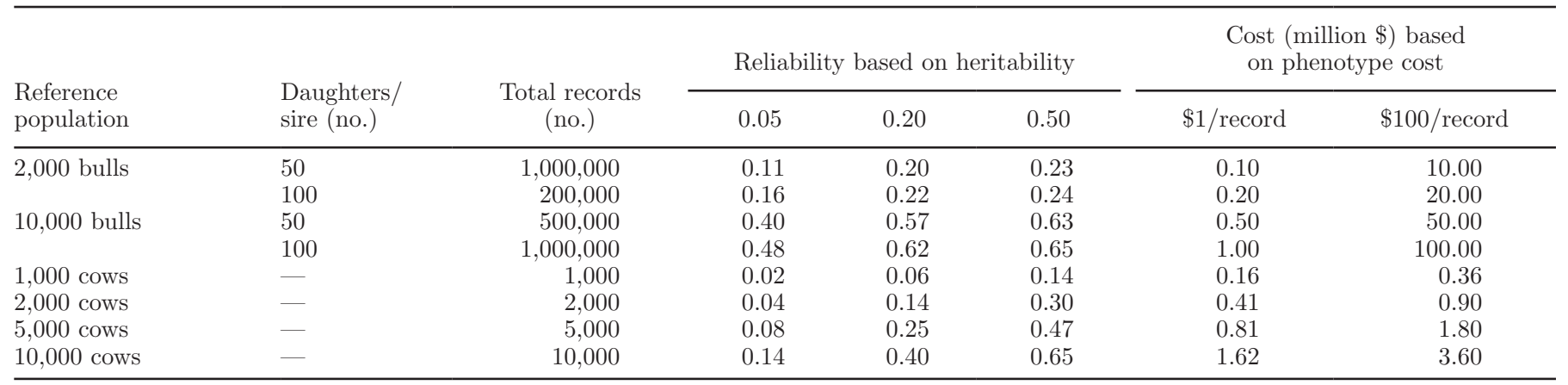

${ }^{1}$ Reliability based on formulas of Daetwyler et al. (2008) and Hayes et al. (2009b) with an effective population size of 100; cows are assumed to have one novel trait record each; costs assume that bull genotypes are already available, cow phenotypes are a fixed cost, and cow genotypes are $\$ 80$ each. 
was investigated from a theoretical point of view with protein yield, predicted BW, and MIR predictions of DMI as indicator traits.

\section{MATERIALS AND METHODS}

\section{Comparing Accuracies from Genomic Validation and from the Daetwyler Formula}

To determine how accurately the Daetwyler formula predicts the accuracy of genomic selection based on cow reference populations, we compared reliabilities calculated with the formula with observed reliabilities from successive validation studies. In those studies, SNP effects were calculated from the phenotypes and genotypes of cows in the reference population. Those SNP effects were then used to calculate direct genomic values (DGV) for recently progeny-tested young bulls, which made up the validation group. All daughters from those bulls had first been removed from the cow reference population so that the SNP effects and bull DGV did not reflect those daughter data. Observed reliabilities were then calculated based on the correlation between the validation bulls DGV and their daughter deviations (DD). A group of validation cows that was separate from the reference population could have been used instead of validation bulls to calculate observed reliabilities. With validation cows, however, observed reliability estimates are more readily affected by differences in the calculation of the theoretical reliabilities of cow breeding values, which are much lower than for progeny-tested bulls, especially for low-heritability traits. As a result, we felt the use of validation bulls would provide more robust estimates of observed reliabilities.

As of December 2014, 17,000 Holstein cows had genotypes in the database used for official Canadian evaluations. Genotypes were from various bead chips that included from 3,000 to 50,000 SNP. For this study, only genotypes from bead chips with 6,000 to 50,000 SNP were used. All genotypes were imputed to 50,000 SNP using version 2 of FImpute (Sargolzaei et al., 2011). Random samples of 2,000,5,000, and 10,000 cows were obtained from that genotyped population after removing all daughters or dams of validation bulls. Cow EBV for traits with various heritability levels (protein yield, mammary system, feet and legs, and heel depth) were obtained from the CDN database and deregressed so that the effect of parent average (PA) was excluded. Type traits with lower heritability were used instead of health and fitness traits, because cow EBV are not routinely calculated for health and fitness traits in Canada.
The effects of SNP markers were estimated with GBLUP, the same method used for official Canadian genetic evaluations (Van Doormaal et al., 2009), using each one of the random cow samples as the reference population. Those SNP effects were used to compute the DGV of 748 bulls progeny tested in 2013 and 2014, which made up the validation group. Realized genomic reliabilities were calculated from the squared correlations $\left(\mathrm{r}^{2}\right)$ of the DGV of the validation bulls with their daughter deviations after adjusting for error variance in the daughter deviations and for prior selection on pedigree as suggested by VanRaden et al. (2009):

$$
\mathrm{REL}_{\mathrm{DGV}}=\left(\mathrm{R}_{\mathrm{DGV}, \mathrm{DD}}^{2} / \mathrm{REL}_{\mathrm{DD}}\right)+\left[\mathrm{REL}_{\mathrm{PA}}-\left(\mathrm{R}_{\mathrm{PA}, \mathrm{DD}}^{2} / \mathrm{REL}_{\mathrm{DD}}\right)\right] \text {. }
$$

The conversion from correlation to reliability is required to make $\mathrm{REL}_{\mathrm{DGV}}$ comparable with the prediction accuracy calculated from the Daetwyler formula, because both are estimates of the square of the correlation between prediction and true genetic value. Generally, genotyped cows are not a random sample of the population, particularly in early years when genomic selection was introduced in Canada. To determine if this had any effect on observed reliabilities, separate evaluation runs were carried out where cows with high genomic reliabilities, or cows that had been genotyped with 50,000 SNP rather than a low density panel, were excluded from the reference population. The effect on prediction accuracies was found to be negligible, however, so those results are not reported.

A similar approach was used to compare predictions from random samples of cow phenotypes and genotypes in the United States. Because of the larger size of the US cow population, however, we investigated reference population sizes of 5,000, 10,000, and 20,000 cows. Evaluations of reference cows and validation bulls were those from the December 2014 official US evaluation. The SNP effects were based on the US genomic evaluation model (VanRaden, 2008). As in Canada, the daughters and dams of validation bulls were excluded from the cow reference population. Prediction accuracy was calculated for several traits with various heritabilities (protein percentage, protein yield, fat yield, productive life, and daughter pregnancy rate). The number of validation bulls for all traits was 1,491.

To assess the effect of formula parameters on differences between observed and predicted accuracy for sire reference populations as well as cow reference populations, we also compared observed reliabilities from Cooper et al. (2014) for the US sire reference population to reliabilities calculated from the Daetwyler formula for a selected group of US traits. The number of reference bulls used was 21,888 for all traits. Effective heritability, 
used in the Daetwyler formula, was calculated as $\mathrm{nh}^{2} /[4$ $\left.+(\mathrm{n}-1) \mathrm{h}^{2}\right]$, where $\mathrm{n}$ is the number of daughters per sire (Cameron, 1997) and was assumed to be 100.

Given the differences between prediction accuracies estimated from validation results and from the Daetwyler formula when $\mathrm{N}_{\mathrm{e}}$ was assumed to be 100 , predictions based on the Daetwyler formula (with $\mathrm{M}_{\mathrm{e}}=2 \mathrm{~N}_{\mathrm{e}} \mathrm{L}$ ) were also calculated for an $\mathrm{N}_{\mathrm{e}}$ of 50 . The use of this smaller $\mathrm{N}_{\mathrm{e}}$ was primarily designed to test the effect of a different $\mathrm{N}_{\mathrm{e}}$ on the results. Besides $\mathrm{M}_{\mathrm{e}}=2 \mathrm{~N}_{\mathrm{e}} \mathrm{L}$ (Hayes et al., 2009b), we used the other frequently used formula for $\mathrm{M}_{\mathrm{e}}: \mathrm{M}_{\mathrm{e}}=2 \mathrm{~N}_{\mathrm{e}} \mathrm{L} / \ln \left(4 \mathrm{~N}_{\mathrm{e}} \mathrm{L}\right)$ (Goddard, 2009). These 2 expressions of $\mathrm{M}_{\mathrm{e}}$ were designated as $\mathrm{M}_{\mathrm{e} 1}$ and $\mathrm{M}_{\mathrm{e} 2}$, respectively.

As in Brard and Ricard (2015), other methods of calculating $\mathrm{M}_{\mathrm{e}}$ were compared with $\mathrm{M}_{\mathrm{e} 1}$ and $\mathrm{M}_{\mathrm{e} 2}: \mathrm{M}_{\mathrm{e}}=$ $4 \mathrm{~N}_{\mathrm{e}} \mathrm{L}(\mathrm{Stam}, 1980)$ and $\mathrm{M}_{\mathrm{e}}=2 \mathrm{~N}_{\mathrm{e}} \mathrm{L} / \ln \left(2 \mathrm{~N}_{\mathrm{e}} \mathrm{L}\right.$ ) (Goddard et al., 2011), as well as other deterministic formulas to predict genomic reliabilities (Goddard, 2009; Goddard et al., 2011). For the cow reference populations and traits considered, however, none of those methods provided better estimates of observed reliabilities than $\mathrm{M}_{\mathrm{e} 1}$ or $\mathrm{M}_{\mathrm{e} 2} ; \mathrm{M}_{\mathrm{e}}=4 \mathrm{~N}_{\mathrm{e}} \mathrm{L}$ resulted in even greater underestimation of observed reliabilities than $\mathrm{M}_{\mathrm{e} 1}$, and all other methods resulted in greater overestimation of observed reliabilities than $\mathrm{M}_{\mathrm{e} 2}$. Therefore, results for these other methods are not presented.

\section{Assessing the Impact of Indicator Traits}

The impact of indicator traits on the prediction accuracy of novel traits was investigated using DMI as an example, with protein yield, predicted BW (from conformation records), and MIR predictions of DMI as indicator traits. As indicated earlier, most of the genetic progress in the North American dairy cattle population today results from the selection of young animals based on their genomic evaluations. Genomic breeding values can be obtained not only for the novel trait itself but also for indicator traits and then combined using the variance-covariance structure between all traits. Alternatively, a multitrait genomic evaluation can be used with all traits evaluated together. The first approach was used for this study. Heritabilities and genetic correlations between traits (Table 3) were based on means of literature estimates (e.g., McParland et al., 2012; Spurlock et al., 2012; Berry et al., 2014a; Manzanilla Pech et al., 2014; and Veerkamp et al., 2014). The source of information available for each trait was 5,000 or 10,000 cows with individual feed intake data (direct evaluation of DMI), 20,000 sires with 100 daughters each for protein yield and predicted BW (i.e., a sire reference population similar in size to that in North America), and either 2,000 or 10,000 sires with predictions of DMI based on MIR data (with the smaller number of sires corresponding to early accumulation of MIR records and the higher number to 5 yr of data collection). All bulls were assumed to have 100 daughters, but effective heritability varies little for these traits once the number of daughters exceeds 50 . Table 4 shows the reliabilities of the DGV for each trait and their expected genetic correlations. All reliabilities were estimated using the Daetwyler formula with $\mathrm{M}_{\mathrm{e}}=2 \mathrm{~N}_{\mathrm{e}} \mathrm{L}$ and $\mathrm{N}_{\mathrm{e}}=100$, which, as shown in the next section, tends to generate conservative estimates for cow reference populations. The expected correlation between the DGV of 2 different traits for the same animal was calculated as the genetic correlation between the traits times the square root of the product of the DGV reliabilities. Correlations between the prediction errors of DGV for different traits were assumed to be negligible. The Excel software program STSELIND, developed by van der Werf (1999), was used to calculate the reliability of DMI for each scenario, based on the genomic reliabilities of intervening traits and their variance-covariance structure.

\section{RESULTS AND DISCUSSION}

\section{Comparing Reliabilities from Genomic Validation and from the Daetwyler Formula}

Reliabilities from the Daetwyler formula are compared with observed reliabilities in Table 5 for Canada and Table 6 for the United States, for cow reference populations of various sizes and different traits. The results are very similar for both countries. When $\mathrm{N}_{\mathrm{e}}$ $=100$, Daetwyler predictions using $\mathrm{M}_{\mathrm{e} 1}$ are system-

Table 3. Heritabilities (on diagonal) and genetic correlations (above diagonal) applied in assessing the impact of indicator traits on prediction accuracy for DMI

\begin{tabular}{lcccc}
\hline Trait & DMI & $\begin{array}{c}\text { Protein } \\
\text { yield }\end{array}$ & $\begin{array}{c}\text { Predicted } \\
\text { BW }\end{array}$ & $\begin{array}{c}\text { Milk } \\
\text { mid-infrared data }\end{array}$ \\
\hline DMI & 0.30 & 0.60 & 0.30 & 0.60 \\
Protein yield & & 0.30 & 0.36 & 0.30 \\
Predicted BW & & 0.50 & 0.40 \\
Milk mid-infrared data & & & 0.25 \\
\hline
\end{tabular}


Table 4. Expected reliabilities ${ }^{1}$ of single-trait direct genomic values (on diagonal) and genetic correlations ${ }^{2}$ between single-trait genomic evaluations of young animals for DMI and indicator traits (above diagonal) using data from 5,000 cows for DMI, 20,000 sires for protein yield and predicted BW, and 2,000 sires for milk midinfrared data ${ }^{3}$

\begin{tabular}{lcccc}
\hline Trait & DMI & $\begin{array}{c}\text { Protein } \\
\text { yield }\end{array}$ & $\begin{array}{c}\text { Predicted } \\
\text { BW }\end{array}$ & $\begin{array}{c}\text { Milk } \\
\text { mid-infrared data }\end{array}$ \\
\hline DMI & 0.20 & 0.24 & 0.12 & 0.13 \\
Protein yield & & 0.79 & 0.29 & 0.13 \\
Predicted BW & & & 0.81 & 0.17 \\
Milk mid-infrared data & & & 0.23 \\
\hline
\end{tabular}

${ }^{1}$ Based on the formula of Daetwyler et al. (2008) with an effective population size of 100 .

${ }^{2}$ Calculated as genetic correlation between traits times the square root of the product of the reliabilities for the traits' direct genomic values.

${ }^{3}$ Sires were assumed to have 100 daughters each.

atically lower than observed reliabilities. The difference is especially large when the size of the cow reference population is limited (2,000 cows for Canada, or 5,000 in both countries) or when the heritability of the trait is low (heel depth in Canada or daughter pregnancy rate in the United States). On the other hand, Daetwyler predictions using $\mathrm{M}_{\mathrm{e} 2}$ (and $\mathrm{N}_{\mathrm{e}}=100$ ) are systematically higher than observed reliabilities, except when the reference cow population size is small and the trait heritability is low. In general, the Daetwyler formula underpredicts accuracy when based on $\mathrm{M}_{\mathrm{e} 1}$, by an average of 0.16 over all cow reference population sizes and traits, and overpredicts it when based on $\mathrm{M}_{\mathrm{e} 2}$, by an average of 0.24 .

Using a value of $\mathrm{N}_{\mathrm{e}}=50$ in the formula with $\mathrm{M}_{\mathrm{e} 1}$ reduces the underestimation, as expected. However, even with such a low value, the formula continues to underpredict observed reliabilities in many cases, particularly when the heritability of the trait is low. Using a value of
$\mathrm{N}_{\mathrm{e}}=50$ in the formula with $\mathrm{M}_{\mathrm{e} 2}$ considerably increases the overprediction of observed reliabilities.

Differences between Daetwyler formula predictions and observed reliabilities are presented in Table 7 for the US Holstein bull reference population. For this population, predictions from the formula with $\mathrm{M}_{\mathrm{e} 1}$ are closer to observed reliabilities than for the cow reference populations considered previously. The average difference between predicted and observed reliabilities for the 5 traits considered is -0.06 . However, the formula tends to slightly underestimate observed reliability for high heritability traits and slightly overestimate it for low heritability traits. The use of $\mathrm{M}_{\mathrm{e} 1}$ with $\mathrm{N}_{\mathrm{e}}=50$ or the use of $\mathrm{M}_{\mathrm{e} 2}$ with $\mathrm{N}_{\mathrm{e}}=100$ both result in severe overpredictions of observed reliabilities.

Part of the differences between predicted and observed reliabilities could also be due to the fact that observed reliabilities are overestimated or underestimated; that is, different from correlations between

Table 5. Comparison between predicted reliability (based on the Daetwyler formula using different estimates of $N_{e}$ and $M_{e}$ ) and observed reliability for various Holstein cow reference populations in Canada ${ }^{1}$

\begin{tabular}{|c|c|c|c|c|c|}
\hline \multirow{2}{*}{ Trait } & \multirow{2}{*}{ No. of cows } & \multirow{2}{*}{$\begin{array}{l}\text { Observed } \\
\text { REL }\end{array}$} & \multicolumn{3}{|c|}{ Daetwyler REL } \\
\hline & & & $\mathrm{M}_{\mathrm{e} 1}$ & $\mathrm{M}_{\mathrm{el}}$ & $\mathrm{M}_{\mathrm{e} 2}$ \\
\hline \multirow{3}{*}{$\begin{array}{l}\text { Protein yield } \\
\left(\mathrm{h}^{2}=0.37\right)\end{array}$} & 2,000 & 0.40 & 0.11 & 0.20 & 0.55 \\
\hline & 5,000 & 0.45 & 0.24 & 0.39 & 0.76 \\
\hline & 10,000 & 0.54 & 0.39 & 0.57 & 0.87 \\
\hline $\begin{array}{l}\text { Mammary system } \\
\left(\mathrm{h}^{2}=0.24\right)\end{array}$ & 10,000 & 0.33 & 0.29 & 0.45 & 0.80 \\
\hline \multirow{3}{*}{$\begin{array}{l}\text { Feet and legs } \\
\left(\mathrm{h}^{2}=0.15\right)\end{array}$} & 2,000 & 0.26 & 0.05 & 0.09 & 0.32 \\
\hline & 5,000 & 0.27 & 0.11 & 0.20 & 0.55 \\
\hline & 10,000 & 0.32 & 0.20 & 0.34 & 0.71 \\
\hline \multirow{3}{*}{$\begin{array}{l}\text { Heel depth } \\
\left(\mathrm{h}^{2}=0.076\right)\end{array}$} & 2,000 & 0.26 & 0.03 & 0.06 & 0.19 \\
\hline & 5,000 & 0.25 & 0.06 & 0.12 & 0.37 \\
\hline & 10,000 & 0.32 & 0.11 & 0.21 & 0.55 \\
\hline
\end{tabular}

$\overline{{ }^{1} \mathrm{REL}}=$ reliability; $\mathrm{M}_{\mathrm{e} 1}=2 \mathrm{~N}_{\mathrm{e}} \mathrm{L}$ as per Hayes et al. (2009b); $\mathrm{M}_{\mathrm{e} 2}=2 \mathrm{~N}_{\mathrm{e}} \mathrm{L} / \mathrm{Log}\left(4 \mathrm{~N}_{\mathrm{e}} \mathrm{L}\right)$ as per Goddard (2009), where $\mathrm{M}_{\mathrm{e}}$ is the number of independently segregating chromosome segments, $\mathrm{N}_{\mathrm{e}}$ is the effective population size, and $\mathrm{L}$ is the length of the genome in Morgans. 
Table 6. Comparison between predicted reliability (based on the Daetwyler formula using different estimates of $\mathrm{N}_{\mathrm{e}}$ and $\mathrm{M}_{\mathrm{e}}$ ) and observed reliability for various Holstein cow reference populations in the United States ${ }^{1}$

\begin{tabular}{|c|c|c|c|c|c|}
\hline Trait & No. of cows & $\begin{array}{l}\text { Observed } \\
\text { REL }\end{array}$ & \multicolumn{3}{|c|}{ Daetwyler REL } \\
\hline \multirow{3}{*}{$\begin{array}{l}\text { Protein percentage } \\
\left(\mathrm{h}^{2}=0.50\right)\end{array}$} & 5,000 & 0.62 & 0.30 & 0.47 & 0.82 \\
\hline & 10,000 & 0.68 & 0.47 & 0.65 & 0.91 \\
\hline & 20,000 & 0.78 & 0.65 & 0.80 & 0.95 \\
\hline $\begin{array}{l}\text { Protein yield } \\
\left(\mathrm{h}^{2}=0.30\right)\end{array}$ & 20,000 & 0.53 & 0.51 & 0.68 & 0.91 \\
\hline \multirow{3}{*}{$\begin{array}{l}\text { Productive life } \\
\left(\mathrm{h}^{2}=0.08\right)\end{array}$} & 5,000 & 0.40 & 0.06 & 0.12 & 0.39 \\
\hline & 10,000 & 0.43 & 0.12 & 0.21 & 0.56 \\
\hline & 20,000 & 0.51 & 0.21 & 0.35 & 0.72 \\
\hline \multirow{3}{*}{$\begin{array}{l}\text { Daughter pregnancy rate } \\
\left(\mathrm{h}^{2}=0.04\right)\end{array}$} & 5,000 & 0.24 & 0.03 & 0.06 & 0.24 \\
\hline & 10,000 & 0.26 & 0.06 & 0.12 & 0.39 \\
\hline & 20,000 & 0.30 & 0.12 & 0.21 & 0.56 \\
\hline
\end{tabular}

${ }^{1} \mathrm{REL}=$ reliability; $\mathrm{M}_{\mathrm{e} 1}=2 \mathrm{~N}_{\mathrm{e}} \mathrm{L}$ as per Hayes et al. (2009b); $\mathrm{M}_{\mathrm{e} 2}=2 \mathrm{~N}_{\mathrm{e}} \mathrm{L} / \mathrm{Log}\left(4 \mathrm{~N}_{\mathrm{e}} \mathrm{L}\right)$ as per Goddard (2009), where $\mathrm{M}_{\mathrm{e}}$ is the number of independently segregating chromosome segments, $\mathrm{N}_{\mathrm{e}}$ is the effective population size, and $\mathrm{L}$ is the length of the genome in Morgans.

DGV and true genetic values. Reliabilities obtained in validation studies, however, remain the best predictions of accuracy available from a practical point of view. They reflect the correlations between predictions and the progeny-based estimates of breeding values that are observed when applying genomic selection in the field. The large differences in predictions when using different $\mathrm{M}_{\mathrm{e}}$ for the same formula, or between results for cow and sire reference populations, tend to point to problems with deterministic formulas rather than with observed reliabilities.

Based on the above, the Daetwyler formula seems to give reasonably accurate estimates for bull reference populations, provided $\mathrm{M}_{\mathrm{e} 1}$ is used and $\mathrm{N}_{\mathrm{e}}$ is estimated correctly. For cow reference populations, the Daetwyler formula with $\mathrm{M}_{\mathrm{e} 1}, \mathrm{M}_{\mathrm{e} 2}$, and the other values of $\mathrm{M}_{\mathrm{e}}$ that we tested, or the formulas proposed by Goddard (2009) or Goddard et al. (2011), were less than satisfactory because they either underpredicted or overpredicted observed reliabilities by large amounts in most cases. Overall, more accurate predictions of accuracy would have been obtained with the Daetwyler formula when averaging the predicted reliabilities obtained with $\mathrm{M}_{\mathrm{e} 1}$ and $\mathrm{M}_{\mathrm{e} 2}$ than when using either $\mathrm{M}_{\mathrm{e} 1}$ or $\mathrm{M}_{\mathrm{e} 2}$. The only exception is for smaller reference population sizes and low heritability, in which case predicted reliabilities based on $\mathrm{M}_{\mathrm{e} 2}$ were closer to observed reliabilities.

One likely problem is that these methods do not effectively account for relationships between selection candidates and the reference population. They also assume that additional individuals added to the reference population are unrelated. However, the accuracy of genomic selection depends not only on linkage disequilibrium but also on family relationships. Accuracy increases as the reference population becomes more related to the predicted population (MacLeod et al., 2014). The short time gap and high degree of relationship between reference and predicted populations in

Table 7. Comparison between predicted reliability (based on the Daetwyler formula using different estimates of $\mathrm{N}_{\mathrm{e}}$ and $\mathrm{M}_{\mathrm{e}}$ ) and observed reliability for Holstein bull reference populations in the United States, for traits with various heritabilities ${ }^{1}$

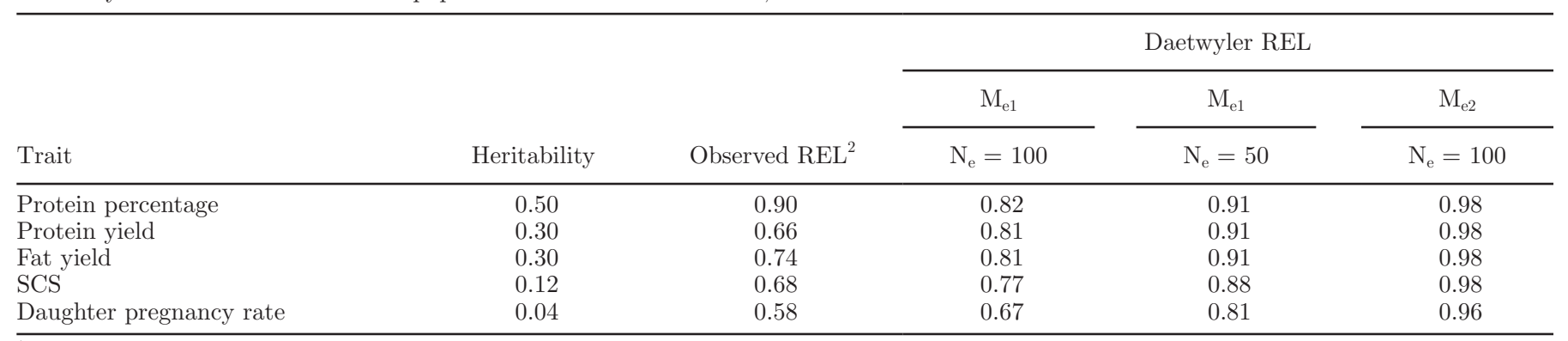

${ }^{1} \mathrm{REL}=$ reliability; $\mathrm{M}_{\mathrm{e} 1}=2 \mathrm{~N}_{\mathrm{e}} \mathrm{L}$ from Hayes et al. (2009b); $\mathrm{M}_{\mathrm{e} 2}=2 \mathrm{~N}_{\mathrm{e}} \mathrm{L} / \mathrm{Log}\left(4 \mathrm{~N}_{\mathrm{e}} \mathrm{L}\right)$ from Goddard (2009), where $\mathrm{M}_{\mathrm{e}}$ is the number of independently segregating chromosome segments, $\mathrm{N}_{\mathrm{e}}$ is the effective population size, and $\mathrm{L}$ is the length of the genome in Morgans.

${ }^{2}$ Observed REL based on reference bulls only ( $\mathrm{n}=21,883$ bulls; Cooper et al., 2014). 
this study led to relatively high observed reliabilities from cow reference populations, which the Daetwyler formula with $\mathrm{M}_{\mathrm{e} 1}$ may have underpredicted.

Deterministic formulas also do not account for the depth of the reference population in terms of the number of generations of animals with genotypes and phenotypes. Realized selection accuracy may be quite different for a reference population composed of 10 generations with 400 animals per generation, compared with one with 2 generations with 2,000 animals each, even though they would have the same total number of animals and therefore the same predicted accuracy when the formula is based only on that number. This may explain in part why comparisons between observed and predicted accuracy are quite different for sire reference populations and cow reference populations, as seen in this study. With sire populations, genotypes are obtained from frozen semen, so that many generations are typically represented. On the other hand, cow reference populations only cover a limited number of generations. Most of the cow genotypes used in our study were collected since 2009, and therefore correspond to a limited number of generations. The same would apply to any recently constituted cow reference population for a novel trait. As a result, for dairy cattle selection, the time gap between the reference population and the selection candidates is usually shorter for cow than for sire reference populations.

A possible approach to address the above shortcomings and obtain better predictions of accuracy of genomic selection when planning for the development of a cow reference population for novel traits would be to select a group of genotyped cows in the same breed that mimics the population structure in which selection for the novel trait will be applied. This should be done for both reference and candidate animals. It would not matter that these animals do not have a novel phenotype, as long as the structure of the population resembles what will eventually occur in practice. The method described by VanRaden (2008) could then be used to calculate individual reliabilities for selection candidates, based on the genomic relationship matrix (G) for the prospective cow reference population, the vector of relationships of the selection candidate with each of the individuals in the reference population $(\mathbf{C})$, and the estimated heritability of the novel trait. The average of individual reliabilities then provides an estimate of observed reliability which accounts for relationships between selection candidates and the reference population. Wientjes et al. (2013) proposed a method to compute $\mathrm{M}_{\mathrm{e}}$ based on the same matrices $\mathbf{G}$ and $\mathbf{C}$. In simulation studies, they found similar reliabilities for the VanRaden (2008) method and for the Daetwyler formula using this new $\mathrm{M}_{\mathrm{e}}$. Therefore, the 2 methods seem roughly equivalent and either could be used.

The fact that the Daetwyler formula based on $M_{e 1}$ underpredicts observed reliabilities is encouraging for those attempting to build cow reference populations for novel traits. Based on our results, it appears possible to obtain moderate accuracies over a fairly wide range of population sizes and heritabilities. Because the effects of population structure and selection have an important effect on the accuracy of genomic predictions (Clark et al., 2012), one might conclude that these results are more applicable to the North American Holstein population, than to other livestock populations. However, the above situation, with intense selection resulting in a smaller $\mathrm{N}_{\mathrm{e}}$ and a relatively short time gap between the reference population and the group of animals for which genomic predictions are used, is commonly found in most selected livestock populations today.

\section{Predicting the Impact of Indicator Traits}

Results on the use of indicator traits for DMI are shown in Table 8. With the assumptions used in this study, the reliability of the DGV of young animals for DMI was 0.20 for 5,000 phenotyped cows and 0.34 for 10,000 phenotyped cows when no indicator traits were used. When only indicator traits were used, the reliability for DMI was 0.34 or 0.43 , depending on whether there were 2,000 or 10,000 sires with MIR data on their daughters. These figures increased to 0.50 and 0.56 , respectively, when both direct and indirect sources of information for DMI were combined. These results show that indicator traits are a powerful way to increase the accuracy of evaluation for novel traits when such traits are expensive or difficult to record. In this example, however, reliability estimates for the cow reference population were likely underestimated by the Daetwyler formula, which was based on $\mathrm{M}_{\mathrm{e} 1}$ and $\mathrm{N}_{\mathrm{e}}=100$. The use of indicator traits would have less effect if direct selection, based on cow genotypes and phenotypes for DMI, had a higher reliability.

Although part of the progress achieved through the use of indicator traits is already occurring as a result of selection for production, the use of DMI phenotypes provides a new avenue for improvement of this trait. One should also note that the efficiency of multi-trait selection depends in large part on the use of accurately estimated genetic correlations between the objective and indicator traits. The collection of a large enough number of phenotypes for a novel trait therefore serves not only to generate genomic predictions for the trait itself, it is also a prerequisite for effective indirect selection. In addition, routine collection of a sufficient 
Table 8. Expected reliabilities of genomic evaluations of young animals for DMI based on a cow reference population with DMI phenotypes and genotypes, or on indicator traits for DMI (protein yield, BW, and milk mid-infrared predictions of DMI), or on a combination of both

\begin{tabular}{|c|c|c|}
\hline Data available & \multicolumn{2}{|c|}{$\begin{array}{l}\text { Reliability based on size } \\
\text { of reference population } \\
\text { with DMI phenotypes }\end{array}$} \\
\hline $\begin{array}{l}\text { Cow reference only (DMI) } \\
\text { Indicator traits only }\end{array}$ & 0.20 & 0.34 \\
\hline Protein yield and BW: 20,000 sires; milk mid-infrared data: 2,000 sires $^{1}$ & 0.34 & 0.34 \\
\hline
\end{tabular}

${ }^{1}$ Reliability based on 100 daughters per sire.

amount of data on a novel trait provides a means to validate the assumptions and effect of indirect selection.

Although the above example dealt with DMI and some of its indicator traits, a similar approach, based on a multitrait genomic evaluation model or on combining DGV for all traits based on their reliabilities and correlations, can be used to increase the accuracy of genetic evaluations for any novel trait. It can also be used to predict the expected reliability achievable for various scenarios, as we have done here.

\section{CONCLUSIONS}

Traits associated with animal health, animal welfare, feed efficiency, and environmental impact are becoming increasingly important for the North American dairy cattle industry. Technological advances make it easier to collect phenotypes for many of these traits, and genomic selection offers new opportunities for their selection. For traits that remain very expensive to collect, the development of cow reference populations is an option that is actively being considered. Validation studies based on random samples of genotyped Holstein cows in North America appear to indicate that the prediction accuracy achievable from such cow reference populations is larger than that predicted by the Daetwyler formula. An example using DMI also shows that the prediction accuracy of novel traits can be substantially increased by the use of indicator traits.

\section{ACKNOWLEDGMENTS}

The authors thank the Canadian Dairy Network (Guelph, ON, Canada) and the Council on Dairy Cattle Breeding (Bowie, MD) for providing the data used in this paper, and S. M. Hubbard (Animal Genomics and Improvement Laboratory, Agricultural Research Service, USDA, Beltsville, MD) for her kind input in manuscript editing and literature review. T. A. Cooper and G. R. Wiggans were supported by USDA Agricultural Research Service appropriated project 124531000-101-00, "Improving Genetic Predictions in Dairy Animals Using Phenotypic and Genomic Information."

\section{REFERENCES}

Attalla, S. A., A. J. Seykora, J. B. Cole, and B. J. Heins. 2010. Genetic parameters of milk ELISA scores for Johne's disease. J. Dairy Sci. 93:1729-1735.

Beavers, L., and B. Van Doormaal. 2015. Pro\$: Genetic selection for profit. Canadian Dairy Network. Accessed Oct. 7, 2015. https:// www.cdn.ca/document.php?id=404.

Berry, D. P., M. P. Coffey, J. E. Pryce, Y. de Haas, P. Løvendahl, N. Krattenmacher, J. J. Crowley, Z. Wang, D. Spurlock, K. Weigel, K. Macdonald, and R. F. Veerkamp. 2014a. International genetic evaluations for feed intake in dairy cattle through the collation of data from multiple sources. J. Dairy Sci. 97:3894-3905.

Berry, D. P., and J. J. Crowley. 2013. Cell Biology Symposium: Genetics of feed efficiency in dairy and beef cattle. J. Anim. Sci. 91:1594-1613.

Berry, D. P., E. Wall, and J. E. Pryce. 2014b. Genetics and genomics of reproductive performance in dairy and beef cattle. Animal 8(Suppl. 1):105-121.

Brard, S., and A. Ricard. 2015. Is the use of formulae a reliable way to predict the accuracy of genomic selection? J. Anim. Breed. Genet. 132:207-217.

Byrem, T. M., H. D. Norman, and J. R. Wright. 2009. Characteristics of milk ELISA results for Johne's disease in US dairy cows. J. Dairy Sci. 92(E-Suppl. 1):386-387. (Abstr.)

Calus, M. P. L., D. P. Berry, G. Banos, Y. de Haas, and R. F. Veerkamp. 2013. Genomic selection: the option for new robustness traits? Adv. Anim. Biosci. 4:618-625.

Cameron, N. D. 1997. Selection Indices and Prediction of Genetic Merit in Animal Breeding. CAB International, Wallingford, UK.

Chapinal, N., A. Koeck, A. Sewalem, D. F. Kelton, S. Mason, G. Cramer, and F. Miglior. 2013. Genetic parameters for hoof lesions in Canadian Holstein cows estimated from hoof trimming records. J. Dairy Sci. 96:2596-2604

Clark, S. A., J. M. Hickey, H. D. Daetwyler, and J. H. van der Werf. 2012. The importance of information on relatives for the prediction of genomic breeding values and the implications for the makeup of reference data sets in livestock breeding schemes. Genet. Sel. Evol. 44:4

Clay, J. S., K. L. Parker Gaddis, and C. Maltecca. 2013. The value of health data from dairy farmers in the United States. ICAR Tech. Ser. 17:137-148.

Cochran, S. D., J. B. Cole, D. J. Null, and P. J. Hansen. 2013. Discovery of single nucleotide polymorphisms in candidate genes associated with fertility and production traits in Holstein cattle. BMC Genet. 14:49. 
Cole, J., K. L. Parker Gaddis, J. S. Clay, and C. Maltecca. 2013. Genomic evaluation of health traits in dairy cattle. ICAR Tech. Ser. $17: 167-175$.

Cooper, T. A., G. R. Wiggans, and P. M. VanRaden. 2014. Including cow information in genomic prediction of Holstein dairy cattle in the US. Commun. 803 in Proc. 10th World Congr. Genet. Appl. Livest. Prod., Vancouver, BC, Canada. Am. Soc. Anim. Sci., Champaign, IL.

Cramer, G., K. D. Lissemore, C. L. Guard, K. E. Leslie, and D. F. Kelton. 2008. Herd- and cow-level prevalence of foot lesions in Ontario dairy cattle. J. Dairy Sci. 91:3888-3895.

Daetwyler, H. D., B. Villanueva, and J. A. Woolliams. 2008. Accuracy of predicting the genetic risk of disease using a genome-wide approach. PLoS ONE 3:e3395.

de Haas, Y., J. E. Pryce, M. P. L. Calus, E. Wall, D. P. Berry, P Løvendahl, N. Krattenmacher, F. Miglior, K. Weigel, D. Spurlock, K. A. Macdonald, B. Hulsegge, and R. F. Veerkamp. 2015. Genomic prediction of dry matter intake in dairy cattle from an international data set consisting of research herds in Europe, North America, and Australasia. J. Dairy Sci. 98:6522-6534.

De Marchi, M., V. Toffanin, M. Cassandro, and M. Penasa. 2014 Invited review: Mid-infrared spectroscopy as phenotyping tool for milk traits. J. Dairy Sci. 97:1171-1186.

Dehareng, F., C. Delfosse, E. Froidmont, H. Soyeurt, C. Martin, N. Gengler, A. Vanlierde, and P. Dardenne. 2012. Potential use of milk mid-infrared spectra to predict individual methane emission of dairy cows. Animal 6:1694-1701.

Dhakal, K., F. Tiezzi, J. S. Clay, and C. Maltecca. 2015a. Inferring causal relationships between reproductive and metabolic health disorders and production traits in first-lactation US Holsteins using recursive models. J. Dairy Sci. 98:2713-2726.

Dhakal, K., F. Tiezzi, J. S. Clay, and C. Maltecca. 2015b. Short communication: Genomic selection for hoof lesions in first-parity US Holsteins. J. Dairy Sci. 98:3502-3507.

Egger-Danner, C., J. B. Cole, J. E. Pryce, N. Gengler, B. Heringstad, A. Bradley, and K. F. Stock. 2015a. Invited review: Overview of new traits and phenotyping strategies in dairy cattle with a focus on functional traits. Animal 9:191-207.

Egger-Danner, C., P. Nielsen, A. Fiedler, K. Müller, T. Fjeldaas, D. Döpfer, V. Daniel, C. Bergsten, G. Cramer, A.-M. Christen, K. F. Stock, G. Thomas, M. Holzhauer, A. Steiner, J. Clarke, N. Capion, N. Charfeddine, E. Pryce, E. Oakes, J. Burgstaller, B. Heringstad, C. Ødegård, and J. Kofler. 2015b. ICAR Claw Health Atlas. Accessed June 11, 2015. http://www.icar.org/Documents/ ICAR_Claw_Health_Atlas.pdf.

Fernando, R. S., S. L. Spahr, and E. H. Jaster. 1985. Comparison of electrical conductivity of milk with other indirect methods for detection of subclinical mastitis. J. Dairy Sci. 68:449-456.

Fogh, A., G. P. Aamand, L. Hjorto, and U. Lauritsen. 2013. Recording of data and identification issues. ICAR Tech. Mtg., Aarhus, Denmark. Accessed Mar. 28 2014. http://www.icar.org/documents/ aarhus_2013/Manuscripts/Fogh.pdf.

Fugate, R. T., L. H. Dauten, G. R. Wiggans, and H. M. White. 2014. Determination of single nucleotide polymorphisms associated with subclinical ketosis in Jersey cattle. J. Dairy Sci. 97(E-Suppl. 1):472. (Abstr.)

Geishauser, T., K. Leslie, J. Tenhag, and A. Bashiri. 2000. Evaluation of eight cow-side ketone tests in milk for detection of subclinical ketosis in dairy cows. J. Dairy Sci. 83:296-299.

Gengler, N., H. Soyeurt, F. Dehareng, C. Bastin, F. Colinet, H. Hammami, and P. Dardenne. 2015. Capitalizing on fine milk composition for breeding and management of dairy cows. J. Dairy Sci. 98(E-Suppl. 1):4. (Abstr.)

Genome Alberta. 2015. New funding to increase feed efficiency and reduce methane emissions in Canada's dairy industry. Livestock Blog, July 22. Accessed Oct. 16, 2015. http://genomealberta. ca/livestock/new-funding-to-increase-feed-efficiency-and-reducemethane-emissions-in-canadas-dairy-industry.aspx.

Goddard, M. 2009. Genomic selection: Prediction of accuracy and maximisation of long term response. Genetica 136:245-257.
Goddard, M. E., B. J. Hayes, and T. H. E. Meuwissen. 2011. Using the genomic relationship matrix to predict the accuracy of genomic selection. J. Anim. Breed. Genet. 128:409-421.

Goodling, R. C., G. W. Rogers, J. B. Cooper, and B. Rune. 2000 Heritability estimates for electrical conductivity of milk and correlations with predicted transmitting abilities for somatic cell scores. J. Dairy Sci. 83(Suppl.1):71. (Abstr.)

Heringstad, B., G. Klemetsdal, and T. Steine. 2007. Selection responses for disease resistance in two selection experiments with Norwegian red cows. J. Dairy Sci. 90:2419-2426.

Hayes, B. J., H. D. Daetwyler, P. Bowman, G. Moser, B. Tier, R. Crump, M. Khatkar, H. W. Raadsma, and M. E. Goddard. 2009a. Accuracy of genomic selection: Comparing theory and results. Proc. Assoc. Advmt. Anim. Breed. Genet. 18:34-37.

Hayes, B. J., P. M. Visscher, and M. E. Goddard. 2009b. Increased accuracy of artificial selection by using the realized relationship matrix. Genet. Res. 91:47-60.

Jamrozik, J., A. Koeck, G. J. Kistemaker, and F. Miglior. 2016 Multiple-trait estimates of genetic parameters for metabolic disease traits, fertility disorders, and their predictors in Canadian Holsteins. J. Dairy Sci. 99:1990-1998. http://dx.doi.org/10.3168/ jds.2015-10505.

Jamrozik, J., A. Koeck, F. Miglior, G. Kistemaker, F. Schenkel, D. Kelton, and B. Van Doormaal. 2013. Genetic and genomic evaluation of mastitis resistance in Canada. Interbull Bull. 47:43-51.

Jaton, C., A. Koeck, F. Miglior, C. A. Price, M. Sargolzaei, and F. S. Schenkel. 2015. Genetic and genomic analysis of superovulatory response in Canadian Holsteins. Interbull Bull. 49:93-96.

Koeck, A., J. Jamrozik, G. J. Kistemaker, F. S. Schenkel, D. F. Kelton, and F. Miglior. 2015a. Estimation of genetic parameters for fertility disorders and their predictors in Canadian Holsteins. Open Industry Session, Genetic Evaluation Board, Canadian Dairy Network, Guelph, ON, Canada. Accessed Oct. 15, 2015. http:// cgil.uoguelph.ca/dcbgc/Agenda1503/DCBGC $\% 20 \mathrm{March} \% 20$ 2015\%20-\%20Astrid\%20Koeck\%20-\%20Fertility\%20Disorders\%20 Evaluation.pdf

Koeck, A., J. Jamrozik, G. J. Kistemaker, F. S. Schenkel, R. K. Moore, D. M. Lefebvre, D. F. Kelton, and F. Miglior. 2015b. Development of genetic evaluations for metabolic disease traits for Canadian dairy cattle. Interbull Bull. 49:76-79.

Koeck, A., F. Miglior, D. F. Kelton, and D. S. Schenkel. 2012c. Genetic parameters for mastitis and its predictors in Canadian Holsteins. J. Dairy Sci. 95:7363-7366.

Koeck, A., F. Miglior, D. F. Kelton, and F. S. Schenkel. 2012a. Investigation of alternative somatic cell count traits to improve mastitis resistance in Canadian Holsteins. J. Dairy Sci. 95:432-439.

Koeck, A., F. Miglior, D. F. Kelton, and F. S. Schenkel. 2012b. Health recording in Canadian Holsteins: Data and genetic parameters. J. Dairy Sci. 95:4099-4108.

Larmer, S. G. 2012. Extent of linkage disequilibrium, consistency of gametic phase and imputation accuracy within and across Canadian dairy breeds. MS Thesis. University of Guelph, Guelph, ON, Canada.

MacLeod, M., B. J. Hayes, and M. E. Goddard. 2014. The effects of demography and long term selection on the accuracy of genomic prediction with sequence data. Genetics 198:1671-1684.

Malchiodi, F., A. Koeck, N. Chapinal, M. Sargolzaei, A. Fleming, D. F. Kelton, F. S. Schenkel, and F. Miglior. 2015. Genetic analyses of hoof lesions in Canadian Holsteins using an alternative contemporary group. Interbull Bull. 49:64-68.

Mallard, B. A., S. Cartwright, M. Emam, K. Fleming, N. Gallo, D Hodgins, M. Paibomesai, K. Thompson-Crispi, and L. WagterLesperance. 2014. Genetic selection of cattle for improved immunity and health. Pages 247-258 in Proc. Western Canadian Dairy Seminar, Edmonton, AB, Canada. University of Alberta.

Manzanilla Pech, C. I. V., R. F. Veerkamp, M. P. L. Calus, R. Zom, A. van Knegsel, J. E. Pryce, and Y. De Haas. 2014. Genetic parameters across lactation for feed intake, fat- and protein-corrected milk, and liveweight in first-parity Holstein cattle. J. Dairy Sci. $97: 5851-5862$ 
McParland, S., G. Banos, B. McCarthy, E. Lewis, M. P. Coffey, B. O'Neill, M. O'Donovan, E. Wall, and D. P. Berry. 2012. Validation of mid-infrared spectrometry in milk for predicting body energy status in Holstein-Friesian cows. J. Dairy Sci. 95:7225-7235.

McParland, S., E. Lewis, E. Kennedy, S. G. Moore, B. McCarthy, M. O'Donovan, S. T. Butler, J. E. Pryce, and D. P. Berry. 2014 Mid-infrared spectrometry of milk as a predictor of energy intake and efficiency in lactating dairy cows. J. Dairy Sci. 97:5863-5871.

METHAGENE. 2015. A European Network: Large-scale methane measurements on individual ruminants for genetic evaluations. Accessed October 2015. http://www.methagene.eu/.

Miglior, F., A. Koeck, J. Jamrozik, F. Schenkel, D. Kelton, G. Kistemaker, and B. Van Doormaal. 2014. Index for mastitis resistance and use of BHBA for evaluation of health traits in Canadian Holsteins. Interbull Bull. 48:73-78.

Oberbauer, A. M., S. L. Berry, J. M. Belanger, R. M. McGoldrick, J. M. Pinos-Rodriquez, and T. R. Famula. 2013. Determining the heritable component of dairy cattle foot lesions. J. Dairy Sci. 96:605-613.

Parker Gaddis, K. L., J. B. Cole, J. S. Clay, and C. Maltecca. 2014. Genomic selection for producer-recorded health event data in US dairy cattle. J. Dairy Sci. 97:3190-3199.

Pryce, J. E., and D. P. Berry. 2014. Genomic breeding values for novel traits such as feed efficiency through female only reference populations. Presentation slides, 39th ICAR Session, Berlin, Germany. Accessed Oct. 15, 2015. http://www.icar.org/ Documents/Berlin_2014/PPTs/Presented/Berry.pdf.

Sargolzaei, M., J. P. Chesnais, and F. S. Schenkel. 2011. FImputeAn efficient imputation algorithm for dairy cattle populations. J. Dairy Sci. 94(E-Suppl. 1):421. (Abstr.)

Sonstegard, T. S., and L. C. Gasbarre. 2001. Genomic tools to improve parasite resistance. Vet. Parasitol. 101:387-403.

Soyeurt, H., F. Dehareng, N. Gengler, S. McParland, E. Wall, D. P. Berry, M. Coffey, and P. Dardenne. 2011. Mid-infrared prediction of bovine milk fatty acids across multiple breeds, production systems, and countries. J. Dairy Sci. 94:1657-1667.

Soyeurt, H., I. Misztal, and N. Gengler. 2010. Genetic variability of milk components based on mid-infrared spectral data. J. Dairy Sci. 93:1722-1728.

Spurlock, D. M., J. C. Dekkers, R. Fernando, D. A. Koltes, and A. Wolc. 2012. Genetic parameters for energy balance, feed efficiency, and related traits in Holstein cattle. J. Dairy Sci. 95:5393-5402.

Spurlock, D. M., R. J. Tempelman, K. A. Weigel, L. E. Armentano, G. R. Wiggans, R. F. Veerkamp, Y. de Haas, M. P. Coffey, E. E. Connor, M. D. Hanigan, C. Staples, and M. J. VandeHaar. 2014. Genetic architecture and biological basis of feed efficiency in dairy cattle. Commun. 287 in Proc. 10th World Congr. Genet. Appl. Livest. Prod., Vancouver, BC, Canada. Am. Soc. Anim. Sci, Champaign, IL.

Stachowicz, K., M. Sargolzaei, F. Miglior, and F. S. Schenkel. 2011. Rates of inbreeding and genetic diversity in Canadian Holstein and Jersey cattle. J. Dairy Sci. 94:5160-5175.

Stam, P. 1980. The distribution of the fraction of the genome identical by descent in finite random mating populations. Genet. Res. 35:131-155.

Tempelman, R. J., D. M. Spurlock, M. Coffey, R. F. Veerkamp, L. E. Armentano, K. A. Weigel, and M. J. VandeHaar. 2015. Heterogeneity in genetic and nongenetic variation and energy sink relationships for residual feed intake across research stations and countries. J. Dairy Sci. 98:2013-2026.
Thompson-Crispi, K. A., H. Atalla, F. Miglior, and B. A. Mallard. 2014a. Bovine mastitis: Frontiers in immunogenetics. Front. Immunol. 5:493.

Thompson-Crispi, K. A., M. Sargolzaei, R. Ventura, M. Abo-Ismail, F. Miglior, F. S. Schenkel, and B. A. Mallard. 2014b. A genome-wide association study of immune response traits in Canadian Holstein cattle. BMC Genomics 15:559.

Thompson-Crispi, K. A., A. Sewalem, F. Miglior, and B. A. Mallard. 2012. Genetic parameters of adaptive immune response traits in Canadian Holsteins. J. Dairy Sci. 95:401-409.

van der Waaij, E. H., M. Holzhauer, E. Ellen, C. Kamphuis, and G. de Jong. 2005. Genetic parameters for claw disorders in Dutch dairy cattle and correlations with conformation traits. J. Dairy Sci. 88:3672-3678.

van der Werf, J. 1999. Single trait selection index calculation. Accessed Oct. 19, 2015. http://www-personal.une.edu.au/ jvanderw/ stselind.xls.

Van Doormaal, B. J., G. J. Kistemaker, P. G. Sullivan, M. Sargolzaei, and F. S. Schenkel. 2009. Canadian implementation of genomic evaluations. Interbull Bull. 40:214-218.

Van Grevenhof, E. M., J. A. M. Van Arendonk, and P. Bijma. 2012. Response to genomic selection: The Bulmer effect and the potential of genomic selection when the number of phenotypic records is limiting. Genet Sel Evol. 44:26.VanRaden, P. M. 2008. Efficient methods to compute genomic predictions. J. Dairy Sci. 91:4414-4423.

VanRaden, P. M. 2008. Efficient methods to compute genomic predictions. J. Dairy Sci. 91:4414-4423.

VanRaden, P. M., C. P. Van Tassell, G. R. Wiggans, T. S. Sonstegard, R. D. Schnabel, J. F. Taylor, and F. S. Schenkel. 2009. Invited review: Reliability of genomic predictions for North American Holstein bulls. J. Dairy Sci. 92:16-24.

Veerkamp, R. F., M. P. L. Calus, G. de Jong, R. van der Linde, and Y. De Haas. 2014. Breeding value for dry matter intake for Dutch bulls based on DGV for DMI and BV for predictors. Commun. 115 in Proc. 10th World Congr. Genet. Appl. Livest. Prod., Vancouver, BC, Canada. Am. Soc. Anim. Sci, Champaign, IL.

Wientjes, Y. C. J., R. F. Veerkamp, and M. P. L. Calus. 2013. The effect of linkage disequilibrium and family relationships on the reliability of genomic prediction. Genetics 193:621-631.

Zare, Y., G. E. Shook, M. T. Collins, and B. W. Kirkpatrick. 2014a. Genome-wide association analysis and genomic prediction of $M y$ cobacterium avium subspecies paratuberculosis infection in US Jersey cattle. PLoS ONE 9:e88380.

Zare, Y., G. E. Shook, M. T. Collins, and B. W. Kirkpatrick. 2014b. Short communication: Heritability estimates for susceptibility to Mycobacterium avium subspecies paratuberculosis infection defined by ELISA and fecal culture test results in Jersey cattle. J. Dairy Sci. 97:4562-4567.

Zwald, N. R., K. A. Weigel, Y. M. Chang, R. D. Welper, and J. S. Clay. 2004a. Genetic selection for health traits using producerrecorded data. I. Incidence rates, heritability estimates, and sire breeding values. J. Dairy Sci. 87:4287-4294.

Zwald, N. R., K. A. Weigel, Y. M. Chang, R. D. Welper, and J. S. Clay. 2004b. Genetic selection for health traits using producerrecorded data. II. Genetic correlations, disease probabilities, and relationships with existing traits. J. Dairy Sci. 87:4295-4302. 